\title{
From Myocardial Infarction to Peripheral Stenting
}

\author{
Fabien Picard $^{\mathrm{a}, \mathrm{b}}$, Victor-Xavier Tadros ${ }^{\mathrm{a}}$, Gilbert Gosselin ${ }^{\mathrm{a}}$
}

\begin{abstract}
Degenerated saphenous vein grafts (SVGs) are associated with high risk of myocardial infarction (MI). They are difficult to treat percutaneously because of large variability in their wall diameters. We report a case of a 71-year-old male, who presented with an acute inferior ST elevation MI (STEMI) 16 years following revascularization with triple coronary artery bypass graft (sequential SVG to the posterior interventricular and to the second marginal branch of the left circumflex artery, and left internal mammal artery to the left anterior descending). Coronary angiography revealed a massive thrombotic occlusion of the second part of the sequential graft, which was aneurysmal just after the posterior interventricular artery. Thromboaspiration was performed and revealed an $8 \mathrm{~mm}$ diameter aneurysmal degenerated graft. We decided to use a balloon-expandable peripheral stent to treat this lesion. TIMI 3 outflow was restored without any no-reflow phenomenon. Patient was discharged to his origin hospital 3 days later. $\mathrm{He}$ had an uneventful evolution at the 3 months follow-up.
\end{abstract}

Keywords: Myocardial infarction; Degenerated saphenous vein graft; Balloon-expandable stent

\section{Introduction}

Saphenous vein graft (SVG) bypass remains widely used for coronary artery bypass revascularization in North America. The mean patency duration of SVGs is approximately $8-9.9$ years [1]. Percutaneous interventions on degenerated SVGs are associated with up to $30 \%$ of short- and long-term major adverse cardiovascular events (MACEs) [2]. Such procedures have evolved to reduce embolization and restenosis. Primary percutaneous interventions on aneurismal degenerated SVGs are difficult because of variable diameters along the SVGs. We report a case of acute myocardial infarction (MI) in which angiography showed an acute thrombosis of a voluminous degenerated SVG. Thrombectomy was realized and angioplasty was performed using a balloon-expandable peripheral stent.

Manuscript accepted for publication March 03, 2016

${ }^{a}$ Hemodynamic Department, Montreal Heart Institute, Montreal, Canada ${ }^{\mathrm{b}}$ Corresponding Author: Fabien Picard, Hemodynamic Department, Montreal Heart Institute, Universite de Montreal, 5000 Belanger Street, Montreal, H1T 1C8, Canada. Email: Fabien.picard@live.fr

doi: http://dx.doi.org/10.14740/jmc2451w

\section{Case Report}

A 71-year-old male was referred to our catheterization center for inferior ST elevation MI (STEMI). The patient underwent triple coronary artery bypass graft (CABG) 16 years previously, with sequential SVG to the posterior interventricular and to the second marginal branch of the left circumflex artery (LCA), and left internal mammal artery (LIMA) to the left anterior descending (LAD). His risk factors were hypertension, diabetes mellitus and dyslipidemia. The patient was regularly followed up and was taking diligently his medication (aspirin, rosuvastatin and metformin).

Intermittent chest pain started 2 days prior to admission. He was initially planned for a non-invasive ischemic test, as there were no electric modifications or cardiac hypersensitive troponin elevations at the emergency room. A more intense and sustained chest pain occurred few hours before his second admission. He was referred to the emergency room and his baseline EKG showed an inferior STEMI. He received intravenous heparin, aspirin and a loading dose of ticagrelor at the admission. He was emergently transferred to the hemodynamics department to perform coronary and bypass angiography. Native coronary angiogram showed a severe stenosis of the distal left main, an occlusion of the proximal LAD, the proximal LCA and the proximal right coronary artery (RCA). The LIMA to the LAD graft was patent. Finally, SVG angiogram showed a massive thrombotic occlusion of the second part of the sequential graft, which was aneurismal just after the posterior interventricular artery (Fig. 1).

A continuous infusion of IIbIIIa inhibitors was started after identifying the culprit lesion. An 8-Fr MP-A1 guiding catheter (Cordis Corp., Miami Lakes, USA) was used to engage the SVG. A BMW universal wire (Abbott Vascular, Santa Clara, USA) easily crossed the occlusion and partially successful thromboaspiration was performed. After pre-dilation with a $2.0 \mathrm{~mm}$ diameter balloon, TIMI 2 flow was restored and the angiogram revealed an $8 \mathrm{~mm}$ diameter (quantitative coronary angiography measurement) aneurysmal degenerated graft (Fig. 2). We decided to use a balloon-expandable peripheral stent to treat this lesion. A $260 \mathrm{~cm}$ Glide hydrosteer wire (St Jude Medical, St Paul, USA) was carefully taken down in the RCA in order to have enough length and backup to bring the stent (Fig. 3). An $8.0 \times 24 \mathrm{~mm}$ Genesis bare metal stent (Cordis Corp, Miami Lakes, USA) was easily taken down and deployed in the SVG (Fig. 4). TIMI 3 outflow was restored without any no-reflow phenomenon. Patient was discharged to his origin hospital 3 days later. He had an uneventful evolution at the 3 months follow-up. 


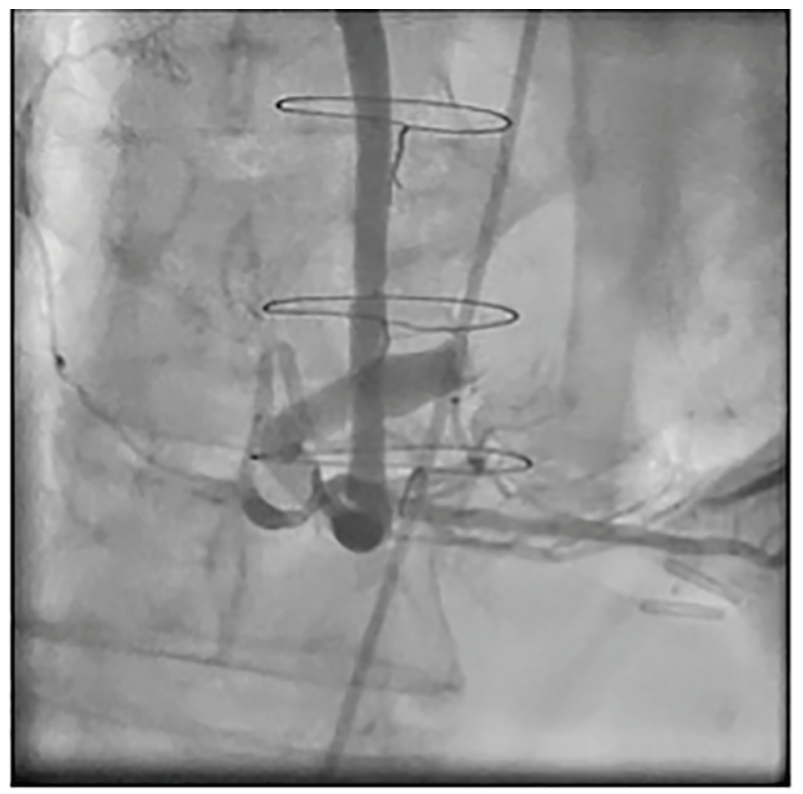

Figure 1. Thrombotic occlusion of the second part of the sequential saphenous vein graft after the posterolateral anastomosis.

\section{Discussion}

Acute MIs involving SVGs are difficult to treat and associated with long-term higher event rates, such as mortality rate of $26 \%$, recurrent MI rate of $26 \%$ and recurrent revascularization rate of $40 \%[3,4]$. Procedural complications and noreflow rates remain high even if distal embolization protection devices have decreased significantly these risks from $20 \%$ to

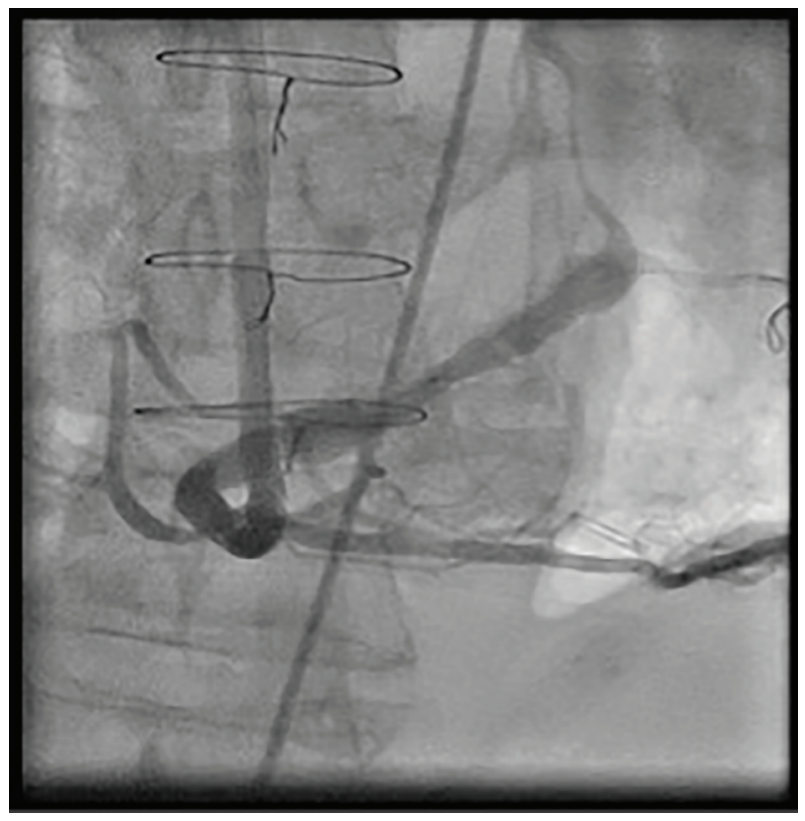

Figure 2. TIMI 2 flow after thrombectomy and predilatation showing an $8 \mathrm{~mm}$ reference diameter on QCA.

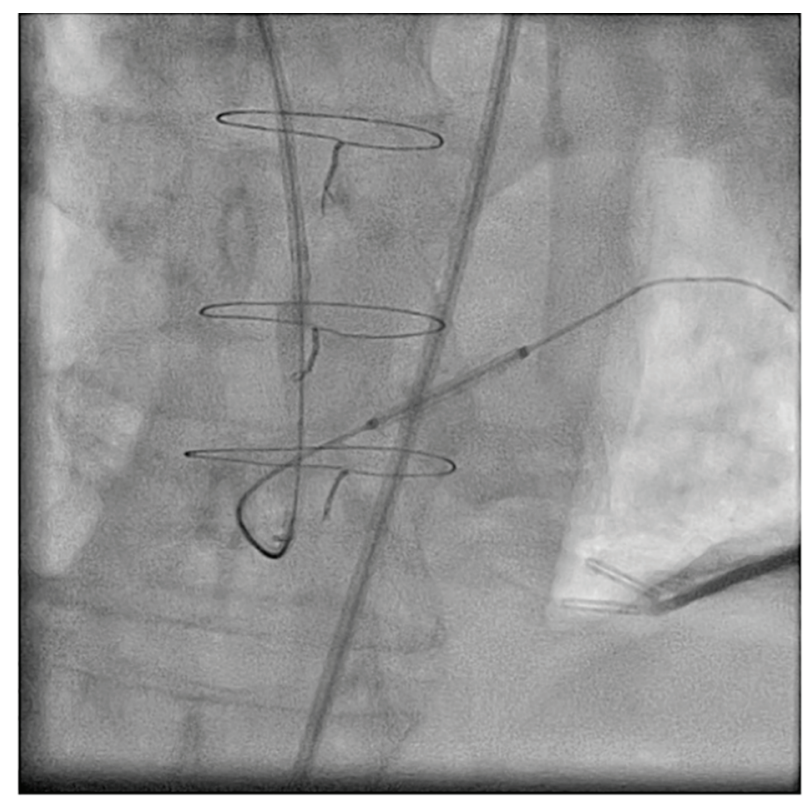

Figure 3. Use of a $260 \mathrm{~cm}$ hydrosteer glide wire to have enough length and backup.

less than $10 \%$ [5]. Mostly because of the large vessel size in degenerated SVG, choice of stent and distal embolization protection strategy is a primary concern. No distal embolization protection device has been used in this case considering the large size of the culprit vessel.

The optimal management of SVG aneurysm remains controversial, especially during acute MI. Traditionally, medical treatment, repeat $\mathrm{CABG}$ and covered stents have been advised in large aneurysm [2].

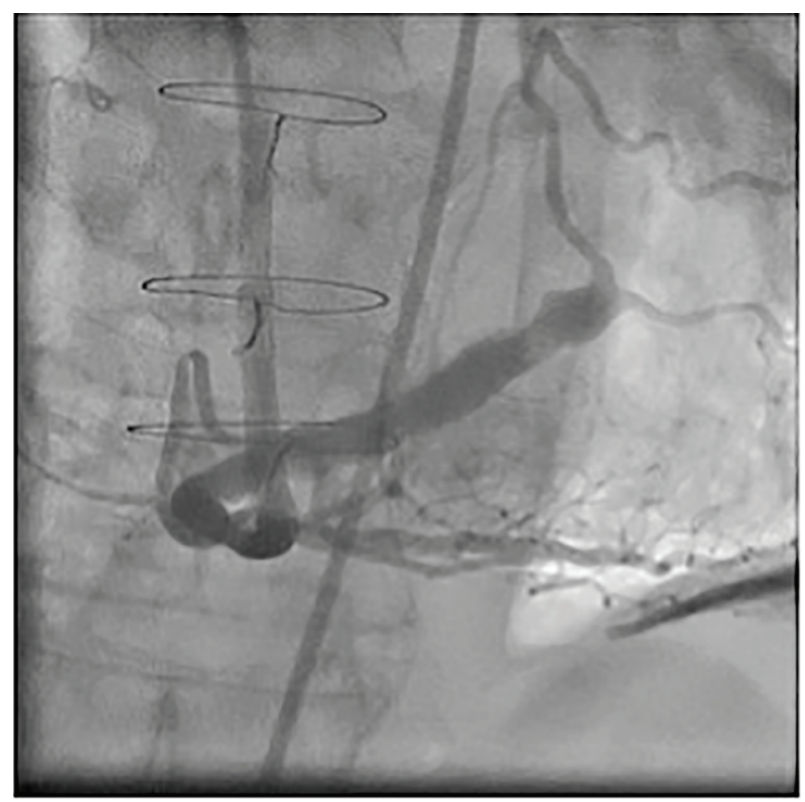

Figure 4. Final result after inflation of a peripheral Genesys $8 \times 24 \mathrm{~mm}$ stent, Cordis. 
To our knowledge, we described the first case of degenerated SVG treated with a balloon-expandable peripheral stent during STEMI. SVG stenting with large peripheral stents seems to be feasible and safe. In addition, peripheral self-expandable stents have already been used safely in elective procedures [6]. Moreover, another type of self-expandable stent, the SESAME stent, has been tested successfully with $14 \%$ MACEs at 9-month follow-up [7]. From a theoretical point, the treatment of degenerated SVGs with balloon-expandable or self-expandable peripheral stents seems safe and feasible in acute MI presentation.

\section{Conclusion}

Degenerated SVGs can be safely treated with balloon-expandable peripheral stent in order to match the large vessel size and avoid strut malposition in acute MIs.

\section{Conflict of Interests}

The authors report no conflict of interest.

\section{References}

1. Peykar S, Angiolillo DJ, Bass TA, Costa MA. Saphenous vein graft disease. Minerva Cardioangiol. 2004;52(5):379390.

2. Marmagkiolis K, Grines C, Bilodeau L. Current percutaneous treatment strategies for saphenous vein graft disease. Catheter Cardiovasc Interv. 2013;82(3):406-413.

3. Nguyen TT, O'Neill WW, Grines CL, Stone GW, Brodie BR, Cox DA, Grines LL, et al. One-year survival in patients with acute myocardial infarction and a saphenous vein graft culprit treated with primary angioplasty. Am J Cardiol. 2003;91(10):1250-1254.

4. Hoffmann R, Nitendo G, Deserno V, Adamu U, Almalla $\mathrm{M}$, Blindt R, Vogt F. Follow-up results after interventional treatment of infarct-related saphenous vein graft occlusion. Coron Artery Dis. 2010;21(2):61-64.

5. Savage MP, Douglas JS, Jr., Fischman DL, Pepine CJ, King SB, 3rd, Werner JA, Bailey SR, et al. Stent placement compared with balloon angioplasty for obstructed coronary bypass grafts. Saphenous Vein De Novo Trial Investigators. N Engl J Med. 1997;337(11):740-747.

6. Gim RD, Bokhari SW, Winters RJ. Novel use of a peripheral, self-expanding nitinol stent in adjunct to excimer laser coronary atherectomy in the treatment of degenerated vein graft disease. Rev Cardiovasc Med. 2005;6(3):173179.

7. Abizaid A, Weiner B, Bailey SR, Londero H. Use of a self-expanding super-elastic all-metal endoprosthesis; to treat degenerated SVG lesions: the SESAME first in man trial. Catheter Cardiovasc Interv. 2010;76(6):781-786. 